\title{
AYUDAS PÚBLICAS Y OFERTA DE SERVICIOS AÉREOS EN LOS AEROPUERTOS ESPAÑOLES $(1996-2010)^{1}$
}

\author{
David Ramos Pérez \\ Departamento de Geografía. Universidad de Salamanca \\ a13004@usal.es \\ Agustín Gámir Orueta \\ Departamento de Humanidades: Historia, Geografía y Arte. Universidad Carlos III de Madrid \\ agamir@hum.uc3m.es \\ Ana Isabel Escalona Orcao \\ Departamento de Geografía y Ordenación del Territorio. Universidad de Zaragoza \\ aescalon@unizar.es
}

\section{RESUMEN}

Las ayudas públicas a las compañías aéreas se han convertido en una fórmula ampliamente utilizada por las administraciones regionales y locales españolas. Supuestamente estas ayudas constituyen el incentivo económico necesario para facilitar la apertura de nuevas rutas o asegurar la continuidad de otras ya existentes. Además, algunos de estos enlaces se consideran básicos para el desarrollo de los territorios a los que sirven. Sin embargo, la concesión de las ayudas se sitúa al margen de la legislación europea, lo que provoca que el manejo de estos fondos pueda quedar excluido del escrutinio público. Un amplio debate sobre los diferentes impactos de esta práctica que permita evaluar la conveniencia de su continuidad resulta insoslayable.

Palabras clave: Liberalización, transporte aéreo, ayudas públicas, España.

Fecha de recepción: abril 2011.

Fecha de aceptación: marzo 2012.

1 Este artículo presenta algunos resultados del proyecto de investigación Las compañías aéreas de tarifas reducidas en España: ayudas públicas, costes socio-ambientales y discurso político, financiado por el Ministerio de Ciencia e Innovación (referencia CSO2009-11317; subprograma GEOG; periodo 2010-2012). 


\section{ABSTRACT}

Public aids to airlines have become a widely used mechanism by Spanish regional and local governments. Supposedly State aid ensures the necessary incentive to create new routes or maintain existing routes, some of them considered essential for regional development. However, the granting of aid remains on the fringes of European legislation, which causes the management of these funds may be excluded from public scrutiny. An extensive discussion on the different impacts of this practice to assess the desirability of its continuity is inevitable.

Key words: Liberalisation, air transport, State aid, Spain.

\section{INTRODUCCIÓN}

Aunque la Geografía no ha permanecido al margen de la abundante literatura académica que ha generado la liberalización del mercado europeo de transporte aéreo, la mayor parte de sus aportaciones se han limitado al análisis de los grandes cambios observados en las redes y flujos de transporte aéreo. Desde enfoques fundamentalmente cuantitativos se ha evaluado el papel de esas redes y flujos en el funcionamiento de una economía mundializada, siendo escasa la atención dedicada a cuestiones de tipo social o ambiental, como han señalado Adey et al. (2007). Por otro lado, el marco institucional en el que se inserta la liberalización apenas ha suscitado preocupación entre los geógrafos, propiciando que el papel de ciertos actores y políticas tenga una presencia limitada en la producción académica más reciente.

En ese sentido, la transferencia de fondos públicos a las compañías aéreas al margen de las modalidades previstas en la legislación comunitaria, con la intención de asegurar la prestación de ciertas conexiones, constituye una práctica sobre la que la reflexión académica es prácticamente nula. Si bien las referencias a la existencia de las mismas se suceden durante los últimos años (Dobruszkes, 2006: 251; Gross y Schröder, 2007: 36; Gerike, 2007: 207; Graham y Shaw, 2008), parece haber pervivido la idea de que afectaban a una pequeña proporción del total de la oferta, por lo que sus repercusiones serían limitadas. Sin embargo, la denuncia contra Ryanair presentada por Air France, basada en las auditorías realizadas por el Tribunal de Cuentas francés en los diferentes aeropuertos del país (Amedeo, 2010a), ha sacado a la luz un fenómeno de mayor magnitud que la esperada, tal y como ya había señalado Ramos Pérez (2006: 414-421).

Las repercusiones de esta práctica no son pequeñas, pues más allá de la ruptura del principio de libre concurrencia, afectan de lleno al marco institucional sobre el que se asienta la liberalización. Al sortear la legislación vigente con la connivencia de una parte de los poderes públicos, resulta legítimo cuestionarse si las leyes quedan reducidas a una mera función ceremonial, impidiendo no sólo la aplicación efectiva de las mismas, sino favoreciendo incluso a unos agentes sobre otros, por utilizar el ya clásico razonamiento de Tool (1977: 837). Por otro lado, el recurso a estas subvenciones demuestra la trascendencia que las instituciones locales y regionales otorgan al transporte aéreo y al turismo como factores de desarrollo territorial, reproduciendo un modelo ya ensayado en la década de los sesenta con las compañías chárter. 
Este artículo cuantifica por primera vez las ayudas a las compañías aéreas en España, partiendo de una recopilación propia de las ayudas públicas concedidas a diversas compañías aéreas durante el periodo 1996-2010 por las administraciones regionales y locales del país. En el primer apartado revisamos los mecanismos previstos en la legislación comunitaria para canalizar las ayudas públicas, así como la relación existente entre las mismas y la creciente competencia entre aeropuertos. Posteriormente presentamos las distintas fuentes utilizadas para la elaboración de la mencionada base de datos, discutiendo las dificultades existentes para tener una información precisa de los desembolsos efectuados. En el tercer apartado analizamos de forma detallada el volumen de las ayudas resultante y su distribución por aeropuertos y compañías, para finalmente interrogarnos sobre el coste variable que supone transportar un pasajero, en función de la compañía o aeropuerto involucrado. Concluimos con una reflexión sobre la conveniencia o no de financiar la puesta en marcha de servicios aéreos, señalando la perentoria necesidad de introducir en el debate las cuestiones sociales, ambientales y energéticas si se quiere evitar la toma de decisiones basadas en argumentos demasiado simplistas.

\section{LAS AYUDAS PÚBLICAS AL TRANSPORTE AÉREO EN LA NORMATIVA DE LA UNIÓN EUROPEA}

El triunfo de la doctrina económica neoliberal durante el último cuarto del siglo XX tuvo un claro reflejo en las políticas de transporte llevadas a cabo en todo el Mundo, al maximizarse los mecanismos de mercado en la provisión de servicios de transporte y limitarse el papel del Estado, bien al de un mero regulador de dicho mercado, bien al de un inversor en aquellas infraestructuras escasamente rentables para la iniciativa privada. La liberalización de los diversos mercados de transporte y la privatización de los antiguos operadores públicos constituyó el corolario habitual de dichos planteamientos. Aunque Docherty et al. (2004) han sugerido que se observa un cierto retroceso del dogma neoliberal como consecuencia de la incapacidad del mercado para hacer frente a algunas externalidades sociales y ambientales, la realidad es que la política de transporte de la mayoría de los países continúa fundamentada en las premisas señaladas, constituyendo un buen ejemplo de ello la Política Común de Transportes de la Unión Europea.

En este contexto se entiende mejor la puesta en marcha, desde finales de los años ochenta, del proceso de liberalización del mercado de transporte aéreo en el interior de la antigua Comunidad Europea, uno de los modos donde la intervención de la iniciativa pública no sólo era significativa, sino especialmente visible a través de las llamadas compañías de bandera controladas por los respectivos Estados. La liberalización llevaba asociada la prohibición de las ayudas de Estado en el sector, lo que implicaba que no podía subvencionarse directamente a ninguna compañía aérea para asegurar su rentabilidad, aunque fuese de titularidad pública, ni otorgarse ayudas específicas para la explotación de conexiones aéreas.

Dichas prácticas eran ampliamente utilizadas por los Estados miembros, como puso de manifiesto un informe publicado por la Comisión a principios de los noventa (CCE, 1992). Ello motivó que la normativa reguladora de la liberalización contemplara algunas excepciones, que posibilitaban el mantenimiento de ayudas públicas, si bien empleando mecanismos que aseguraban una mayor transparencia. Se permitió así la transferencia de fondos públicos 
a las compañías de bandera en determinadas circunstancias (DOCE, 1994) y se estableció la posibilidad de declarar como obligación de servicio público (OSP) ciertos enlaces intracomunitarios ${ }^{2}$, lo que abría la puerta a la subvención directa a dichas rutas. Ambas fórmulas están bien documentadas, tanto porque se requiere la conformidad de la Comisión Europea para su aprobación, lo que genera numerosos informes oficiales al respecto, como por interés académico que ha suscitado esta excepción en la aplicación de la legislación comunitaria (Doganis 2001: 201-207; Dobruszkes, 2007).

Sin embargo, estos dos mecanismos no son los únicos utilizados en la actualidad para subvencionar a las compañías aéreas que operan en el mercado comunitario, existiendo otros que se sitúan al margen de la legalidad vigente. Puede considerarse que el reconocimiento formal de dicha situación por parte de las instituciones comunitarias tiene lugar en 2002. En esa fecha sale a la luz pública la investigación que la Comisión Europea realizaba al Gobierno de Valonia y a la empresa pública gestora del aeropuerto de Charleroi por el trato de favor dispensado a la compañía Ryanair en dichas instalaciones, lo que se materializaba en notables transferencias de dinero público a la misma (DOCE, 2004). La constatación de que esas prácticas no constituían una excepción se produce en febrero de 2005, cuando la Comisión Europea presenta una propuesta de directrices, aprobada a finales de ese año (DOCE, 2005), que autorizaban las ayudas públicas a las compañías aéreas que pusieran en marcha nuevas rutas que afectaran a aeropuertos regionales con un tráfico anual inferior a cinco millones de pasajeros ${ }^{3}$. Eso sí, siempre y cuando se utilizara para ello el procedimiento establecido en las directrices con la finalidad de asegurar una mayor transparencia en la concesión de estos fondos. El papel de determinados grupos de presión, como los gobiernos regionales, los aeropuertos y las compañías de bajo coste, fue determinante para que la normativa no acabara con las ayudas públicas sino que estableciera criterios para su concesión (ELFAA, 2004a y 2004b; FARE, 2005; ARC, 2005; DOUE, 2004). Hasta julio de 2007 la Comisión había aprobado ayudas para la apertura de nuevas rutas por valor de 163 millones de euros, al tiempo que se sucedían las investigaciones sobre casos similares al de Charleroi (CCE, 2007).

De alguna manera, la aprobación de estas directrices abre una nueva etapa, en la que la competencia entre aeropuertos se suma a la competencia entre aerolíneas. Esa evolución era previsible en un contexto marcado por la liberalización del mercado y la creciente entrada de capital privado en los aeropuertos. La nueva situación lleva a que un número creciente de aeropuertos se haya volcado en la captación de aerolíneas y en la diversificación de sus

2 «Todo Estado miembro [...] podrá imponer la obligación de servicio público en relación con servicios aéreos regulares a un aeropuerto que sirva a una región periférica o en desarrollo situada en su territorio, o en una ruta de baja densidad de tráfico que sirva un aeropuerto regional de su territorio, cuando dicha ruta se considere esencial para el desarrollo económico de la región en la que está situado el aeropuerto, en la medida necesaria para garantizar en dicho trayecto una adecuada prestación de servicios aéreos regulares que cumplan determinadas normas en materia de continuidad, regularidad, capacidad y precios que las compañías aéreas no asumirían si únicamente tuvieran en cuenta su interés comercial.» (DOCE, 1992, artículo 4.1.a; DOUE, 2008, artículo 16.1)

3 Este umbral se amplía hasta los 10 millones de pasajeros en el caso de aeropuertos situados en regiones desfavorecidas, como las ultraperiféricas, las de baja densidad demográfica, las que cuentan con nivel de vida anormalmente bajo y las afectadas por una grave situación de subempleo. En esos casos, las ayudas, siempre decrecientes en el tiempo, pueden prolongarse durante cinco años, en lugar de los tres fijados como máximo con carácter general. 
rutas aéreas. De ahí el auge experimentado en los últimos años por el denominado marketing aeroportuario, un conjunto de técnicas diseñadas para alcanzar dichos objetivos, entre las que encontraríamos, además de la publicidad y la asistencia a ferias especializadas, los incentivos económicos para facilitar la apertura de nuevas rutas (Graham, 2003; Halpern y Niskala, 2008). Por tanto, las directrices comunitarias institucionalizan esa técnica de marketing, limitándose a estipular los criterios para que, en principio, dichos incentivos no vulneren la competencia en el seno del mercado comunitario.

Por muy sorprendente que pudiera parecer, esta nueva fórmula, que permitía legalizar procedimientos vigentes antes de la aprobación de las directrices, tampoco ha evitado que las subvenciones públicas sigan fluyendo hacia las compañías aéreas por cauces no reconocidos en la normativa comunitaria. Era lo que ponían de manifiesto las informaciones que regularmente aparecían en la prensa europea y es lo que ha venido a confirmar de forma oficial la detallada auditoría de los aeropuertos franceses realizada por el Tribunal de Cuentas de ese país (Cours des Comptes, 2008).

\section{FUENTES PARA EL ANÁLISIS DE LAS AYUDAS EN ESPAÑA}

De lo expuesto en el apartado anterior se deduce que, los únicos mecanismos legalmente habilitados para que los poderes públicos puedan fomentar la explotación de conexiones aéreas, son las declaraciones de obligación de servicio público (OSP) y las ayudas a la puesta marcha de rutas que cumplan las condiciones estipuladas en las directrices aprobadas en 2005 .

En el caso español existen diecisiete rutas consideradas OSP. Entre ellas, dieciséis presentan carácter interinsular -trece en Canarias y tres en Baleares-, estando cubiertas sin necesidad de recurrir a subvención alguna. La única ruta sujeta a OSP en la que se compensa económicamente al operador ${ }^{4}$ es el enlace Almería-Sevilla, donde la inversión pública se estima que alcanzará los 12 millones de euros durante el periodo de cuatro años de vigencia de la OSP (MFOM, 2009). Air Nostrum, la compañía franquiciada de Iberia, resultó ganadora del concurso convocado por el Ministerio de Fomento, comprometiéndose a cubrir la ruta hasta el año 2013. Por otro lado, ninguna administración pública española se ha acogido a las directrices que permiten las subvenciones para la puesta en marcha de enlaces desde aeropuertos regionales.

Sin embargo, los datos oficiales ofrecen una imagen muy parcial de la realidad, siendo mucho mayor el número de conexiones aéreas operadas gracias a los fondos que transfieren diversas administraciones públicas a algunas aerolíneas. Una simple búsqueda en las hemerotecas de las ediciones digitales y en papel de la prensa local española basta para confirmar este extremo. La mayor transparencia, difusión pública y control que exigen los cauces previstos por la legislación son, paradójicamente, algunos de los factores que ayudan a entender el nulo interés que muestran por estos instrumentos las distintas instituciones que

4 Esta situación va a cambiar a partir de 2012, ya que la compañía que cubría las rutas El Hierro-Gran Canaria, La Gomera-Tenerife Norte, La Gomera-Gran Canaria y Gran Canaria-Tenerife Sur sin recibir compensación económica alguna ha manifestado al Ministerio de Fomento su intención de abandonar la operación de las mismas. Para asegurar su mantenimiento, el Ministerio de Fomento va a destinar 3,1 millones anuales que cubrirán el déficit de explotación de dichos servicios (MFOM, 2011). 
promueven los enlaces aéreos. En ese sentido, las exigencias que plantean al respecto las compañías aéreas son claves para comprender esta opacidad, algo que llegan a reconocer algunos políticos. ${ }^{5}$

Conviene recordar al respecto que las directrices comunitarias aprobadas a finales de 2005 indican que las subvenciones públicas a las aerolíneas deben tener una limitación temporal, sirviendo únicamente de estímulo para la creación de nuevas rutas o el refuerzo de las existentes con frecuencias adicionales. Pero el recurso a otras fórmulas permite subvertir estos condicionantes, por lo que una aerolínea puede recibir de forma indefinida este tipo de ayudas sin modificar su oferta de vuelos.

Este comportamiento, alejado de la transparencia que debe guiar la gestión pública, anticipa las dificultades con las que se va a encontrar cualquier intento de conocer de forma detallada el volumen total al que ascienden dichas ayudas. De hecho, quienes negocian este tipo de subsidios por parte de las administraciones públicas, suelen mantener una notable discreción al respecto, como pudimos comprobar al estudiar la implantación de Ryanair en Zaragoza (Escalona et. al., 2008). El extremo hermetismo con el que se llegan a tratar estos temas conduce a situaciones que incluso bordean la legalidad democrática. No puede recibir otro calificativo la decisión que en 2008 tomó el Gobierno Foral de Navarra de sustraer del control parlamentario el contenido de un convenio suscrito entre una sociedad pública regio-

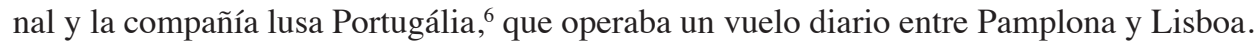

A pesar de esta opacidad hemos podido confeccionar una base de datos que permite una aproximación al fenómeno, basándonos en cuatro tipos de fuentes:

- La consulta de la prensa local resultó muy útil para tener una primera imagen de la difusión espacial de estas ayudas y de las diferentes fórmulas utilizadas para favorecer la implantación de rutas aéreas. La trascendencia que se da en estos medios a la llegada de una compañía aérea, más aún si es de bajo coste, al considerar que supone un estímulo para el desarrollo de la provincia o región concernida, facilitó notablemente nuestra tarea. Asimismo, las discrepancias políticas que suelen emerger respecto a las fórmulas de promoción de los aeropuertos propician filtraciones a la prensa, no sólo de la cantidad de dinero destinada a tal efecto, sino incluso de las cláusulas incluidas en los contratos (Alonso, 2010, 5).

- Los boletines o diarios oficiales de las Comunidades Autónomas y Provincias nos han permitido rastrear aquellos fondos que se concedían mediante convocatorias públicas y que, por tanto, aparecen recogidos en dichas publicaciones oficiales. Son los datos más fiables de los que se dispone, dando cuenta de una parte significativa de los fondos trasferidos, aunque no de la totalidad de los mismos.

5 De acuerdo con la presidenta de la Diputación de León, Isabel Carrasco, el Consorcio que promociona el aeropuerto leonés no puede destinar fondos para que la compañía Ryanair comience a operar en el mismo porque se niega a que esas ayudas se transfieran mediante un concurso público para la inserción de publicidad (Europa Press, 2010a).

6 Como puede comprobarse en el Diario de Sesiones del Parlamento de Navarra (DSPN, 2008, 9-10), al diputado Txentxo Jiménez Hervás se le negó el acceso al convenio suscrito entre la sociedad pública SPRIN (Sociedad de Promoción de Inversiones e Infraestructuras de Navarra) y la mencionada aerolínea, en el que se fijan las contraprestaciones económicas para el mantenimiento de la conexión con la capital portuguesa. El Consejero de Economía y Hacienda del gobierno navarro se amparaba en la existencia de un contrato mercantil para justificar tal decisión. 
- Los diarios de sesiones de los Parlamentos o Asambleas autonómicas, en los que se recoge el contenido de las distintas intervenciones que tienen lugar en estas cámaras, incluyendo las respuestas a las preguntas que formulan los diputados. Durante los últimos años, el debate político sobre las fórmulas adecuadas para atraer a los operadores de bajo coste ha llegado a diversos parlamentos regionales. La lectura de estos diarios, además de permitirnos comprobar el papel como motor de desarrollo que otorgan la mayoría de los políticos al transporte aéreo, nos informa en algunos casos sobre las cantidades pagadas a determinadas compañías.

- Finalmente, en el caso concreto de la Comunidad Valenciana, han resultado sumamente útiles los informes elaborados por la Sindicatura de Comptes, el Tribunal de Cuentas autonómico, un órgano encargado del control externo del sector público. Lamentablemente, no todas las Comunidades cuentan con esta institución, ni los informes anuales que elaboran los tribunales existentes se interesan de manera tan detallada por ciertos tipos de contratos, como sí ocurre en el caso de la Sindicatura.

La información contenida en estas fuentes, aunque incompleta, nos permite identificar los diferentes mecanismos utilizados para canalizar los fondos, así como ofrecer una primera estimación del montante de esas ayudas y de su distribución espacial, cuestión esta última que trataremos detalladamente en los próximos apartados.

Respecto a los mecanismos de captación de fondos públicos, hemos podido identificar la existencia de estrategias diferenciadas entre Air Nostrum y Ryanair, las compañías que como veremos reciben más del $80 \%$ de las subvenciones. La franquiciada de Iberia llegó a negociar directamente con las administraciones públicas subvenciones para compensar las pérdidas derivadas de la explotación de ciertos servicios, como ocurría en Murcia o Zaragoza (BORM, 1996; BOA, 1999). Posteriormente, ante la evidente irregularidad que suponía esta práctica, se ha generalizado la convocatoria de concursos para la inserción de publicidad en las aeronaves de la compañía. ${ }^{7}$

En cuanto a Ryanair, la vinculación se establece mediante contratos mercantiles de carácter confidencial entre una empresa pública y la aerolínea, en los que se compromete una determinada subvención en función del número de rutas abiertas o del número de pasajeros transportados. El trabajo del Tribunal de Cuentas de Francia ha permitido saber que las cláusulas varían de un contrato a otro, existiendo algunos más favorables para las instituciones públicas y otros para la compañía. En todo caso, las dificultades para conocer el monto total de las ayudas son mucho mayores que en el caso de Air Nostrum. ${ }^{8}$ Por tanto, los datos referidos a esta aerolínea tienen menos fiabilidad que los relacionados con Air Nostrum, siendo claramente inferiores a la cifra real.

7 Aunque la finalidad siga siendo la misma, la convocatoria del concurso aporta una mayor transparencia al proceso y permite conocer mejor el volumen de ayudas que recibe la compañía, aumentando. Un buen ejemplo lo proporciona el reconocimiento a la prensa de Carlos Bartomeu, consejero delegado de Air Nostrum, de que la compañía había recibido 9,9 millones en 2003 en concepto de «apoyos a la explotación de instituciones autonómicas y municipales» (Cinco Días, 2004). Nuestra base de datos recoge para dicha fecha un total de 9,8 millones, lo que demuestra la fiabilidad de los datos relativos a las ayudas que recibe Air Nostrum.

8 Por ejemplo, sabemos de la existencia de estos acuerdos en Valladolid y Zaragoza desde el año 2004 pero desconocemos el valor de los mismos, salvo para el último ejercicio en la capital aragonesa. 


\section{LA CUANTÍA DE LAS AYUDAS Y SU DISTRIBUCIÓN}

Entre 1996 y 2010, diversas administraciones públicas españolas, distribuidas por catorce comunidades autónomas y la ciudad de Melilla, han desembolsado un mínimo de 297 millones de euros con el objeto de facilitar la puesta en marcha o asegurar la continuidad de alguna ruta aérea en 26 aeropuertos del país ${ }^{9}$. Sin duda, esta cifra está por debajo de lo transferido en realidad, pero da una idea aproximada de la magnitud que ha alcanzado esta práctica. La desagregación anual de este montante muestra un aumento paulatino de la inversión a lo largo del periodo considerado, con un refuerzo claro de la misma a partir del año 2005 . En 2010, el último ejercicio considerado, la inversión ha rondado los 42 millones de euros, prácticamente igualando el máximo alcanzado en 2006 (figura 1).

ESTIMACIÓN DE LOS FONDOS PÚBLICOS RECIBIDOS POR LAS AEROLÍNEAS EN ESPAÑA (1996-2010)

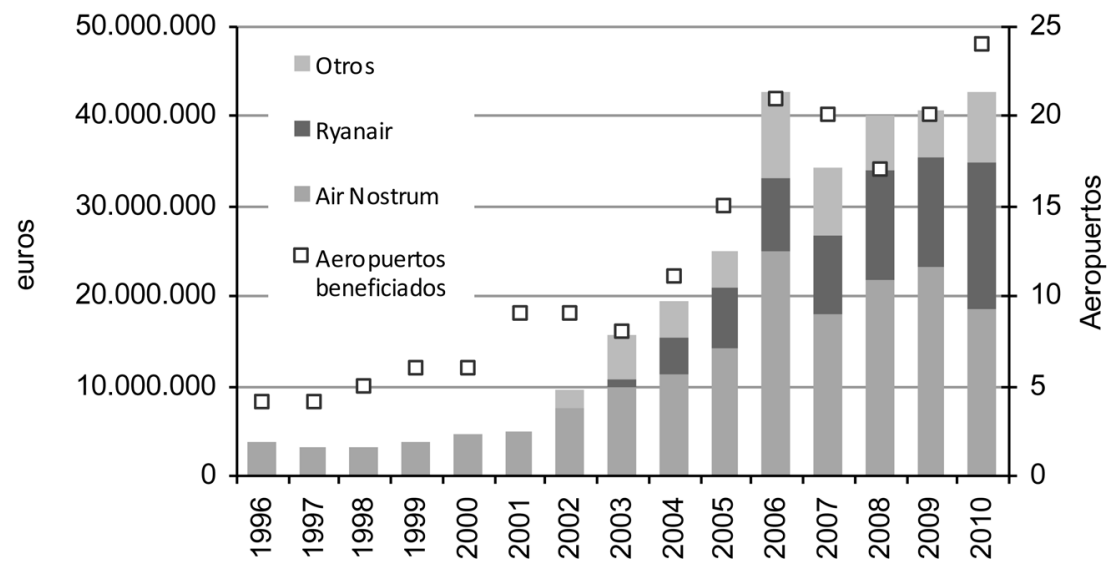

Fuente: Base de datos de ayudas públicas.

Más del 80\% de esos fondos se los han repartido Air Nostrum y Ryanair (tabla 1). En tercer lugar se sitúa Lagun Air, compañía de vida efímera que recibió un trato preferente de la Junta de Castilla y León en su intento de potenciar los aeropuertos de la región. Y en cuarta posición encontramos el conjunto formado por Vueling y Clickair, ahora fusionadas y que desde el año 2007 han comenzado a recibir una fuente inyección de fondos públicos.

9 En los casos de Girona y Granada diversas instituciones privadas han costeado una parte de la inversión, aunque no disponemos de información detallada al respecto. En un reciente comunicado de prensa firmado por el presidente de la Diputación de Girona, el delegado del Gobierno de la Generalitat y el presidente de la Cámara de Comercio, en el que se exigía el traspaso del aeropuerto a la Generalitat, se afirmaba que la aportación privada para el desarrollo de rutas desde el aeropuerto suponía la mitad de la inversión realizada. A falta de un conocimiento desagregado de las cifras y dado que este hecho no se repite en ningún otro caso, hemos preferido trabajar con el montante total que incluye aportaciones públicas y privadas. 
Tabla 1

DISTRIBUCIÓN DE LAS AYUDAS PÚBLICAS POR AEROPUERTOS (1996-2010)

\begin{tabular}{|c|c|c|c|c|c|c|c|}
\hline \multirow{2}{*}{ Aeropuerto } & \multirow{2}{*}{ Pax 2009} & \multirow{2}{*}{$\%$} & \multicolumn{4}{|c|}{ Ayudas (euros) } & \multirow{2}{*}{$\%$} \\
\hline & & & Air Nostrum & Ryanair & Otras & Total & \\
\hline Alicante & 9.122 .469 & $25,5 \%$ & 71740980 & 500000 & & 72240980 & $246 \%$ \\
\hline Valencia & 4.729 .592 & $13,2 \%$ & 11.140 .000 & & & & 24,010 \\
\hline Girona & 5.265 .482 & $14,7 \%$ & 1.670 .814 & 26.966 .667 & 5.057 .086 & 33.694 .566 & $11,5 \%$ \\
\hline Fuerteventura & 3.671 .597 & $10,3 \%$ & & 898.000 & & 898.000 & $0,3 \%$ \\
\hline Subtotal & 22.789 .140 & $63,6 \%$ & 73.411 .794 & 28.364 .667 & 5.057 .086 & 106.833 .546 & $36,4 \%$ \\
\hline Santiago & 1.926 .618 & $5,4 \%$ & 213.333 & 4.957 .024 & 1.566 .667 & 6.737 .024 & $2,3 \%$ \\
\hline Murcia & 1.630 .634 & $4,6 \%$ & 7.515 .395 & & 300.000 & 7.815 .395 & $2,7 \%$ \\
\hline Asturias & 1.311 .528 & $3,7 \%$ & 7.700 .000 & & 1.136 .490 & 8.836 .490 & $3,0 \%$ \\
\hline Granada & 1.174 .725 & $3,3 \%$ & & 4.220 .000 & & 4.220 .000 & $1,4 \%$ \\
\hline Vigo & 1.103 .162 & $3,1 \%$ & 213.333 & & 866.667 & 1.080 .000 & $0,4 \%$ \\
\hline Reus & 1.689 .279 & $4,7 \%$ & 900.000 & 13.000 .000 & & 13.900 .000 & $4,7 \%$ \\
\hline Coruña & 1.056 .239 & $2,9 \%$ & 213.333 & & 10.434 .667 & 10.648 .000 & $3,6 \%$ \\
\hline Santander & 957.272 & $2,7 \%$ & 15.173 .279 & 14.653 .885 & & 29.827 .163 & $10,2 \%$ \\
\hline Subtotal & 10.849 .457 & $30,3 \%$ & 31.928 .674 & 36.830 .909 & 14.304 .490 & 83.064 .072 & $28,3 \%$ \\
\hline Zaragoza & 526.718 & $1,5 \%$ & 9.321 .264 & 3.000 .000 & 1.750 .000 & 14.071 .264 & $4,8 \%$ \\
\hline Valladolid & 358.328 & $1,0 \%$ & 9.473 .815 & n.d. & 5.295 .542 & 14.769 .357 & $5,0 \%$ \\
\hline Pamplona & 327.037 & $0,9 \%$ & 150.253 & & 2.960 .000 & 3.110 .253 & $1,1 \%$ \\
\hline Melilla & 287.458 & $0,8 \%$ & 8.000 .000 & & & 8.000 .000 & $2,7 \%$ \\
\hline San Sebastián & 307.217 & $0,9 \%$ & 425.000 & & & 425.000 & $0,1 \%$ \\
\hline León & 94.245 & $0,3 \%$ & 10.755 .502 & & 15.733 .333 & 26.488 .835 & $9,0 \%$ \\
\hline Badajoz & 71.178 & $0,2 \%$ & 10.049 .000 & & & 10.049 .000 & $3,4 \%$ \\
\hline Ciudad Real & 53.557 & $0,1 \%$ & & n.d. & 2.710 .000 & 2.710 .000 & $0,9 \%$ \\
\hline Salamanca & 52.860 & $0,1 \%$ & 8.655 .502 & & 2.333 .333 & 10.988 .835 & $3,7 \%$ \\
\hline Vitoria & 38.742 & $0,1 \%$ & 1.298 .186 & 1.050 .000 & & 2.348 .186 & $0,8 \%$ \\
\hline Logroño & 22.286 & $0,1 \%$ & 2.103 .000 & & & 2.103 .000 & $0,7 \%$ \\
\hline Albacete & 14.073 & $0,0 \%$ & 2.950 .000 & & & 2.950 .000 & $1,0 \%$ \\
\hline Burgos & 23.439 & $0,1 \%$ & 4.015 .502 & & & 4.015 .502 & $1,4 \%$ \\
\hline Lleida & 0 & $0,0 \%$ & & & 1.600 .000 & 1.600 .000 & $0,5 \%$ \\
\hline Subtotal & 2.177 .138 & $6,1 \%$ & 67.197 .023 & 4.050 .000 & 32.382 .209 & 103.629 .232 & $35,3 \%$ \\
\hline TOTAL & 35.815 .735 & $100 \%$ & 172.537 .491 & 69.245 .575 & 51.743 .785 & 293.526 .851 & $100 \%$ \\
\hline
\end{tabular}

Fuente: Base de datos de ayudas públicas y estadísticas oficiales AENA [www.aena.es].

Aunque la compañía valenciana franquiciada de Iberia ha sido un receptor privilegiado de estas ayudas, en 2010 Ryanair prácticamente ha igualado tanto el montante de los subsidios que percibe como el número de aeropuertos en los que opera gracias a los mismos. Su progresiva implantación en las rutas domésticas, para las que tradicionalmente se recurría a Air Nostrum, constituye la explicación más plausible de este cambio.

Ahora bien, ¿qué proporción de la oferta de frecuencias y asientos estaría afectada por estas ayudas? Ofrecer un dato preciso es complicado, porque cuando se firman contratos de publicidad, los pliegos no especifican las rutas a operar. Si consideramos que dichos fondos aseguran el mantenimiento de todas las rutas que explota la compañía beneficiada por el contrato en cada aeropuerto y tomamos como referencia una semana de febrero de 2010, obtenemos un total de 172 rutas operadas gracias a alguna subvención pública (figura 2). Ello supone que el 7,5\% de los vuelos y el 6,6\% de la capacidad ofertada con origen los aeropuertos españoles está vinculada a la inversión que realizan ciertas administraciones 


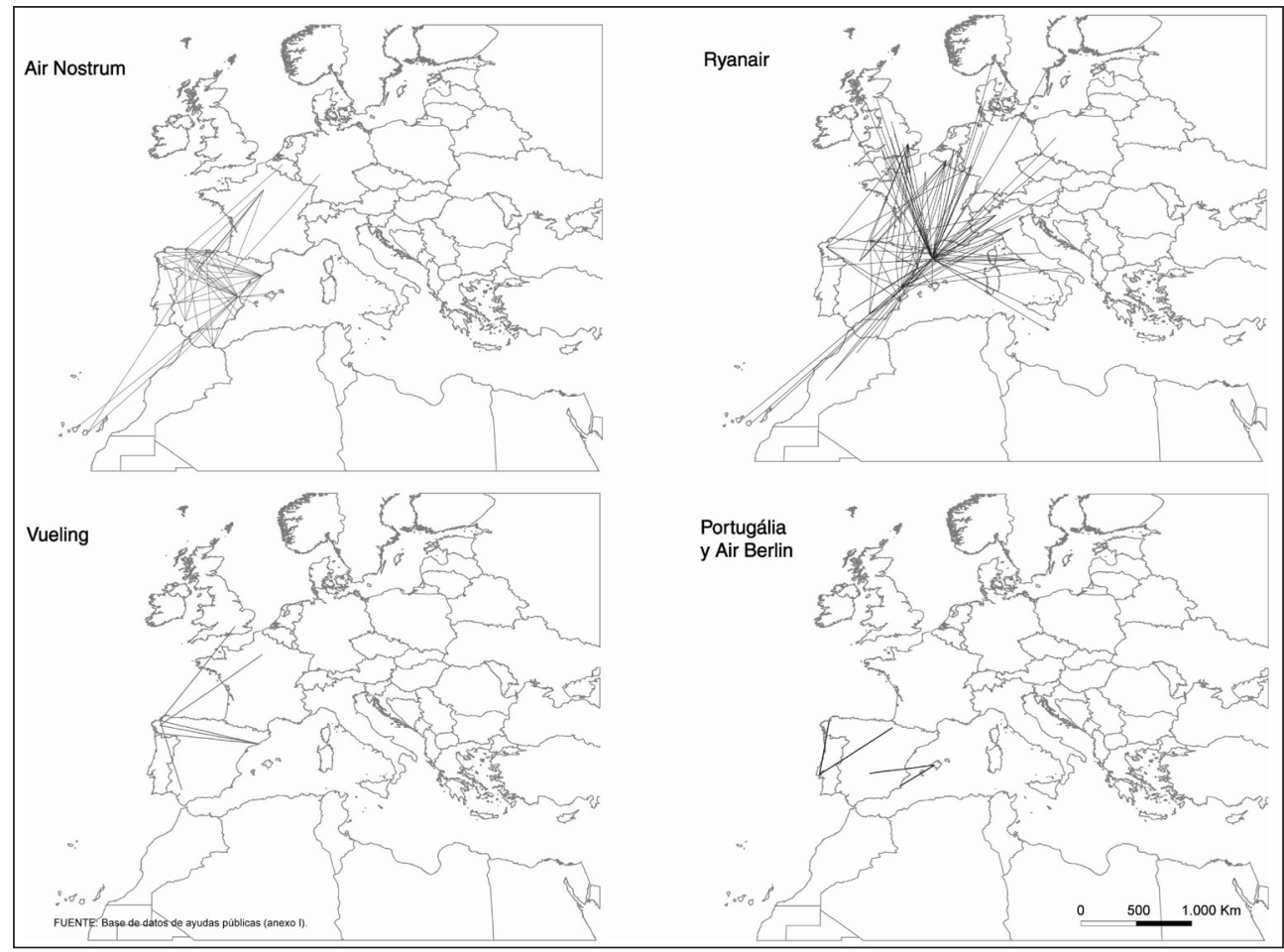

(tabla 2). Aunque no existen estudios similares a escala europea que permitan un análisis comparado de dichas cifras, Dobruszkes (2007) ha señalado que las rutas operadas en régimen de obligación de servicio público en el mercado comunitario que reciben algún tipo de subvención, suponían en enero de 2005 el 3,6\% del total de vuelos operados y el 1,9\% de la oferta de asientos. En todo caso, si consideramos que en Francia también se han encontrado mecanismos de ayudas a las compañías al margen de los previstos en la legislación, estos datos refuerzan la idea de que una proporción relevante de la oferta comunitaria está vinculada a la transferencia de fondos públicos negociados directamente entre administraciones y aerolíneas.

Como era previsible, la mayor parte de los aeropuertos que se ha beneficiado de estas ayudas cuenta con un tráfico reducido (figuras 3 y 4). De los veintiséis aeropuertos en los que se han encontrado ayudas públicas, catorce cuentan con un tráfico anual inferior al medio millón de pasajeros (tabla 1). Estas instalaciones forman parte de lo que hemos definido como pequeños aeropuertos regionales españoles (Gámir Orueta y Ramos Pérez, 2011), caracterizados por prestar servicio a capitales de provincia de tamaño medio o pequeño ubicadas en territorios no excesivamente dinámicos desde el punto de vista económico. Si a ello unimos que la notable inversión realizada en la red viaria y ferroviaria ha reducido los tiem- 


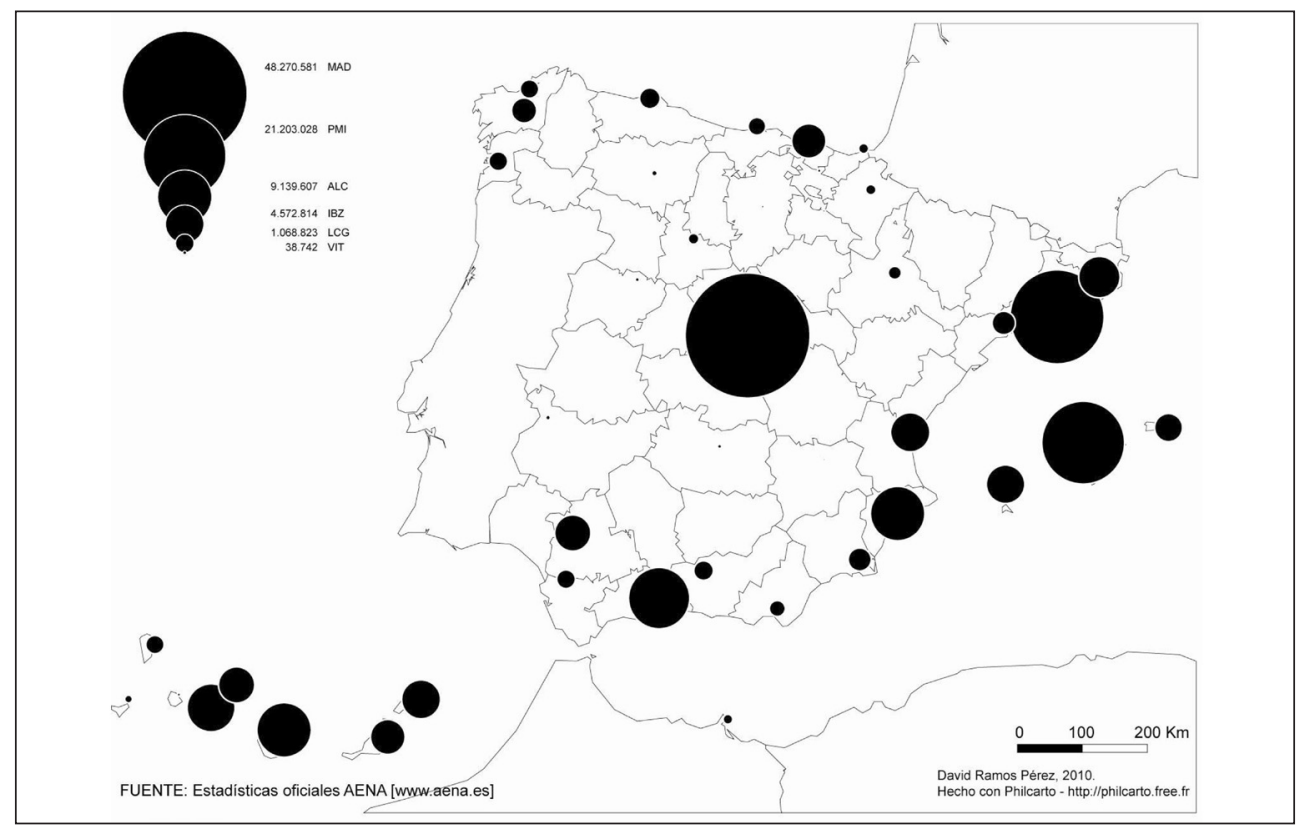

Figura 4

DISTRIBUCIÓN AYUDAS PÚBLICAS TRANSFERIDAS POR AEROPUERTOS (1996-2010)

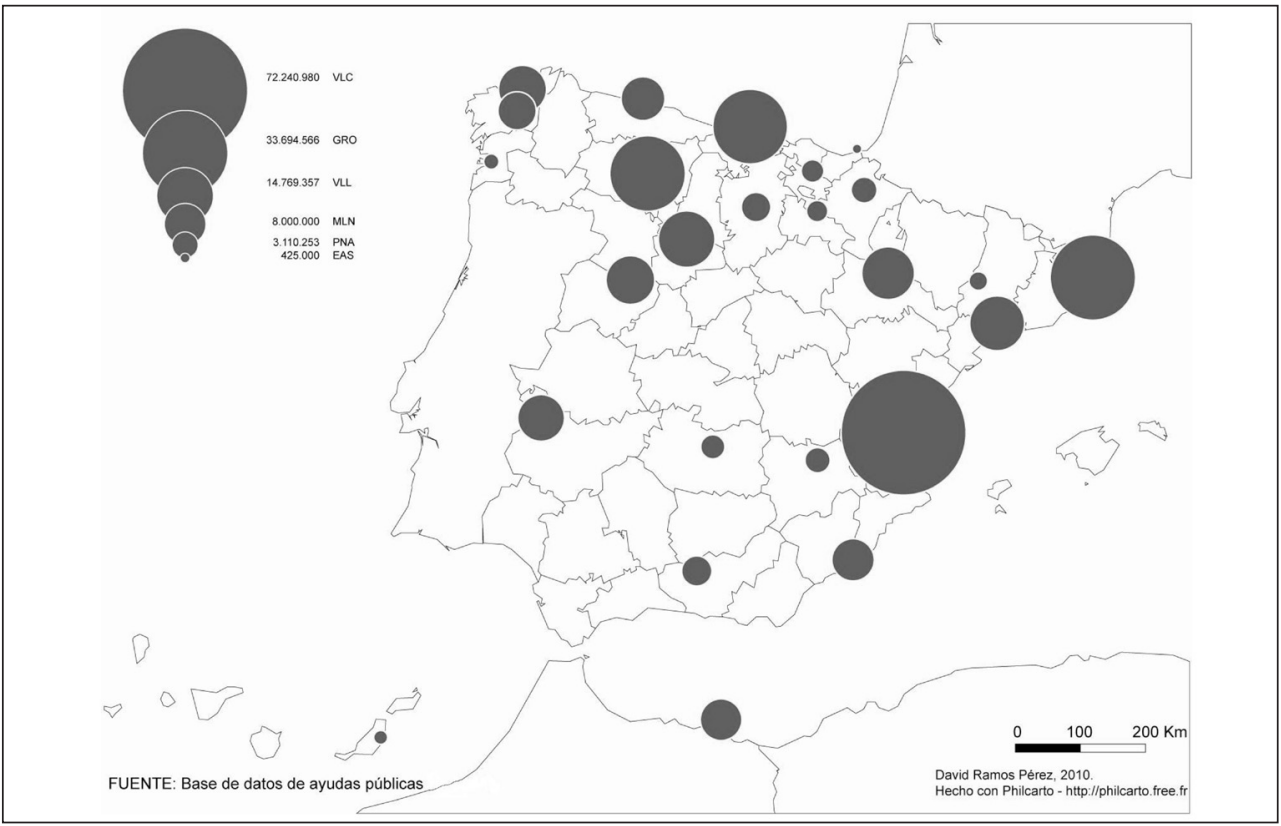


pos de acceso a otros aeropuertos relativamente próximos y dotados de una oferta de vuelos mayor y más diversificada, se comprende que su demanda potencial sea limitada.

Aún siendo mayoritarios, sólo han concentrado el 35,3\% de los fondos transferidos a las aerolíneas durante el periodo estudiado, destacando claramente sobre el conjunto el aeropuerto de León, gracias a los más de 26 millones aportados por las instituciones desde 1999. Una prueba de las dificultades que tienen para asegurar un mínimo de tráfico la encontramos en el hecho de que siete de ellos eran completamente dependientes de las ayudas públicas en el año 2010. Más significativo aún es el caso de Zaragoza, ya que sirviendo a una capital regional con una notable actividad industrial, la dependencia de las ayuda superaba el $90 \%$ (tabla 2). Precisamente, Zaragoza es junto con Valladolid la única instalación de este tipo en la que Ryanair cuenta con una presencia ya consolidada mediante la implantación progresiva de nuevas rutas. En los restantes opera de forma casi exclusiva Air Nostrum.

Tabla 2

OFERTA DE VUELOS Y ASIENTOS DEPENDIENTE DE LAS AYUDAS PÚBLICAS (FEBRERO 2010)

\begin{tabular}{|c|c|c|c|c|c|c|}
\hline \multirow{2}{*}{ Aeropuerto } & \multicolumn{2}{|c|}{ Oferta total } & \multicolumn{4}{|c|}{ Oferta subvencionada } \\
\hline & Vuelos & Asientos & Vuelos & $\%$ & Asientos & $\%$ \\
\hline Santander & 122 & 11.881 & 122 & 100,0 & 11.881 & 100,0 \\
\hline Reus & 34 & 6.426 & 34 & 100,0 & 6.426 & 100,0 \\
\hline Valladolid & 40 & 3.390 & 40 & 100,0 & 3.390 & 100,0 \\
\hline Badajoz & 18 & 900 & 18 & 100,0 & 900 & 100,0 \\
\hline Lleida & 4 & 720 & 4 & 100,0 & 720 & 100,0 \\
\hline Ciudad Real & 4 & 691 & 4 & 100,0 & 691 & 100,0 \\
\hline Salamanca & 9 & 450 & 9 & 100,0 & 450 & 100,0 \\
\hline Burgos & 7 & 350 & 7 & 100,0 & 350 & 100,0 \\
\hline Albacete & 6 & 300 & 6 & 100,0 & 300 & 100,0 \\
\hline Gerona & 296 & 55.527 & 293 & 99,0 & 55.377 & 99,7 \\
\hline Zaragoza & 44 & 5.509 & 41 & 93,2 & 4.969 & 90,2 \\
\hline León & 28 & 1.960 & 22 & 78,6 & 1.100 & 56,1 \\
\hline Santiago & 137 & 21.971 & 72 & 52,6 & 10.276 & 46,8 \\
\hline Valencia & 499 & 56.977 & 275 & 55,1 & 23.753 & 41,7 \\
\hline Granada & 100 & 15.726 & 28 & 28,0 & 5.292 & 33,7 \\
\hline A Coruña & 107 & 15.118 & 36 & 33,6 & 4.286 & 28,4 \\
\hline Murcia & 77 & 10.360 & 29 & 37,7 & 2.106 & 20,3 \\
\hline Vigo & 118 & 15.198 & 21 & 17,8 & 1.830 & 12,0 \\
\hline Asturias & 121 & 15.397 & 21 & 17,4 & 1.194 & 7,8 \\
\hline Pamplona & 68 & 4.630 & 6 & 8,8 & 114 & 2,5 \\
\hline Subtotal & 1.839 & 243.481 & 1.088 & 59,2 & 135.405 & 55,6 \\
\hline TOTAL ESPAÑA & 14.510 & 2.049 .671 & 1.088 & 7,5 & 135.405 & 6,6 \\
\hline
\end{tabular}

NOTA: Cálculos propios a partir de la base de datos OAG Max.

Ocho aeropuertos en los que se han detectado ayudas presentan un tráfico comprendido entre el millón y los dos millones de pasajeros. Se trata de un grupo compuesto por instalaciones situadas en la periferia geográfica de España: fundamentalmente en la cornisa can- 
tábrica y el sureste peninsular. Exceptuando Reus, esta ubicación alejada de los centros de poder político y económico del país, unida a las dificultades orográficas en la relación con el centro peninsular, origina tiempos de viaje superiores a las cuatro horas en las conexiones terrestres con Madrid y Barcelona. Si a ello unimos el elevado volumen de población de los espacios a los que sirven, se explica que durante décadas hayan mantenido una oferta estable de conexiones con ambas ciudades.

Este grupo ha acaparado el 28,3\% de las ayudas, aunque el mayor esfuerzo inversor se ha realizado en Santander y Reus, cuya oferta es también la más dependiente de las ayudas. Sin embargo, con la excepción de Reus, cuentan con una mayor variedad de operadores que los aeropuertos del grupo anterior, lo que constituye una fortaleza ante los cambios de estrategia de las aerolíneas. Además, su mayor demanda potencial, fruto de las características apuntadas, los hace más atractivos para las compañías de bajo coste, contando todos ellos con la presencia de alguna.

Finalmente, encontramos los casos de Alicante, Valencia, Girona y Fuerteventura, aeropuertos que aún superando ampliamente los cuatro millones de pasajeros, se benefician de generosas ayudas de las administraciones públicas a Ryanair y Air Nostrum. Entre los cuatro concentran el 36,4\% de las subvenciones contabilizadas desde 1996, lo que constituye una notable polarización de las mismas. Sin duda, lo llamativo no es tanto la cuantía detectada en Fuerteventura y Girona, donde los fondos se han utilizado para consolidar una de las mayores bases operativas de Ryanair ${ }^{10}$, sino la magnitud de los fondos en Valencia y Alicante. Ambos aeropuertos son, a priori, los grandes beneficiados de la destacada aportación que la Generalitat Valenciana ha otorgado a Air Nostrum durante el periodo analizado. Aunque junto con Madrid y Barcelona, Valencia es el aeropuerto que acapara un mayor número de rutas de la compañía, el elevado montante de las ayudas también se explica por la ubicación de la sede operativa de la compañía en esta región, lo que genera centenares de empleos. Una vez la Generalitat ha decido cortar con este apoyo, que ha supuesto más de 5 millones de euros anuales entre 1996 y 2010, habrá que esperar a ver si la compañía opta por algún cambio en su estrategia operativa respecto a la Comunidad Valenciana.

\section{IV. ¿CUÁNTO CUESTA TRANSPORTAR UN PASAJERO?}

La conclusión que se obtiene de los datos presentados en el apartado anterior es que los servicios aéreos que continúan financiados por las administraciones en el seno de un mercado liberalizado, van mucho más allá de las rutas declaradas obligación de servicio público. Y que la demanda potencial de una ruta ha dejado de ser el único factor determinante para la puesta en marcha de una conexión aérea, siempre y cuando exista una ayuda económica que permita enjugar las pérdidas. En ese sentido, parece que la pregunta pertinente ha pasado a ser cuánto cuesta que una compañía aérea opere en un aeropuerto, como atinadamente se señalaba en un portal de noticias económicas a principios de noviembre de 2010 (Otto, 2010).

10 Este hecho, unido a la proximidad de Barcelona, explica que el tráfico del aeropuerto se multiplicara por ocho entre 2000 y 2009. 
La pregunta admite diversas respuestas en función aeropuerto considerado y de la compañía que percibe la ayuda. La base de datos con la que contamos nos permite conocer, para un amplio número de casos, el coste anual que supone cada vuelo realizado y cada pasajero transportado. En la tabla 3 se presenta una selección de casos, agrupados por compañías aéreas, que dan una idea bastante precisa de la diversidad de situaciones que se presentan.

Tabla 3

COSTE ECONÓMICO POR VUELO Y PASAJERO EN ALGUNOS AEROPUERTOS - AÑO 2007

\begin{tabular}{|c|c|c|c|c|c|c|c|}
\hline \multicolumn{2}{|c|}{ Compañía } & \multirow{2}{*}{$\begin{array}{l}\text { Aeropuerto } \\
\text { Zaragoza }\end{array}$} & \multirow{2}{*}{$\frac{\text { Pasajeros }}{76.109}$} & \multirow{2}{*}{$\begin{array}{c}\text { Vuelos } \\
2.663\end{array}$} & \multirow{2}{*}{$\frac{\text { Subvención }(€)}{3.945 .000}$} & \multirow{2}{*}{$\frac{€ / \mathrm{Pax}}{51,83}$} & \multirow{2}{*}{$\frac{€ / \text { Vuelo }}{1.481,4}$} \\
\hline \multirow{11}{*}{ 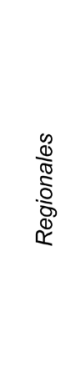 } & Air Nostrum & & & & & & \\
\hline & Air Nostrum & Logroño (a) & 22.032 & 1.227 & 1.051 .500 & 47,73 & 857,0 \\
\hline & Air Nostrum & Albacete & 13.432 & 550 & 580.000 & 43,18 & $1.054,5$ \\
\hline & Air Nostrum & Castilla y León (a) & 242.617 & 8.871 & 8.031 .003 & 33,10 & 905,3 \\
\hline & Air Nostrum & Badajoz & 74.932 & 2.376 & 1.700 .000 & 22,69 & 715,5 \\
\hline & Air Nostrum & Asturias (a) & 112.577 & 3.157 & 2.500 .000 & 22,21 & 791,9 \\
\hline & Air Nostrum & Santander & 432.483 & 10.970 & 2.580 .999 & 5,97 & 235,3 \\
\hline & Air Nostrum & Murcia & 136.396 & 3.564 & 651.000 & 4,77 & 182,7 \\
\hline & Portugália & Coruña & 2.853 & 297 & 216.000 & 75,71 & 727,3 \\
\hline & Portugália & Pamplona & 3.638 & 303 & 240.000 & 65,97 & 792,1 \\
\hline & Lagun Air & León & 72.112 & 2.740 & 2.500 .000 & 34,67 & 912,4 \\
\hline \multirow{8}{*}{$\begin{array}{l}0 \\
\frac{0}{0} \\
0 \\
.0 \\
\mathscr{\varpi}\end{array}$} & Ryanair & Vitoria (b) & 82.277 & 585 & 450.000 & 5,47 & 769,2 \\
\hline & Ryanair & Santiago & 246.149 & 1.722 & 1.224 .720 & 4,98 & 711,2 \\
\hline & Ryanair & Santander & 305.954 & 2.153 & 1.134 .667 & 3,71 & 527,0 \\
\hline & Ryanair & Granada & 339.220 & 2.269 & 1.000 .000 & 2,95 & 440,7 \\
\hline & Ryanair & Reus & 603.696 & 3.973 & 1.000 .000 & 1,66 & 251,7 \\
\hline & Ryanair & Girona & 4.259 .715 & 28.559 & 3.500 .000 & 0,82 & 122,6 \\
\hline & Clickair & Coruña & 261.562 & 2.256 & 2.400 .000 & 9,18 & $1.063,8$ \\
\hline & Easyjet & Asturias & 200.597 & 1.829 & 289.821 & 1,44 & 158,5 \\
\hline \multirow{2}{*}{ Otras } & Spanair & Coruña & 308.359 & 3.237 & 420.000 & 1,36 & 129,7 \\
\hline & Spanair & Pamplona & 70.130 & 1.075 & 500.000 & 7,13 & 465,1 \\
\hline
\end{tabular}

FUENTE: Base de datos de ayudas públicas y estadísticas oficiales AENA [www.aena.es].

NOTAS: (a) Año 2009; (b) Año 2006

De la lectura de los datos se deduce que los enlaces operados por Ryanair tienen para las administraciones públicas un coste por pasajero transportado muy inferior al de los explotados por aerolíneas regionales como Air Nostrum, Portugália o la extinta Lagun Air. De hecho, las contrapartidas que la franquiciada de Iberia recibe en Murcia y Cantabria, aún siendo las más bajas que percibe por pasajero, son muy similares a los valores máximos que ha logrado embolsarse Ryanair en Vitoria y Santiago. En ese sentido, el coste que tiene para las administraciones públicas una conexión servida por Air Nostrum es muy similar al que se observa en múltiples rutas declaradas obligación de servicio público en el mercado comunitario (Williams y Pagliari, 2004). Los 37 euros por asiento ofertado que se obtiene como promedio en los enlaces que tienen tal consideración en Francia constituyen un buen ejemplo de ello (Dobruszkes, 2007).

De todas formas, más allá de esa apreciación general, el amplio abanico de observaciones con que contamos para Ryanair y Air Nostrum nos permite constatar que ambas compañías 
no plantean siempre las mismas exigencias. Así, cuanto menor es el tráfico de la aerolínea en un aeropuerto, mayor es la subvención por pasajero que recibe para operar en el mismo. En los aeropuertos servidos por Ryanair esa ratio oscila entre los 0,82 euros por pasajero de Girona y los 5,47 de Vitoria, o sea, una relación de 1 a 7. En aquellos donde opera Air Nostrum las diferencias entre aeropuertos son mayores, ya que encontramos desde los 4,7 euros por pasajero de Murcia hasta los 51,8 de Zaragoza, una relación de 1 a 11. Llama poderosamente la atención el contraste que existe entre Murcia y Santander y el resto de instalaciones. Ello podría estar indicando, bien una mayor capacidad de la compañía para imponer sus condiciones en aeropuertos en los que opera en solitario y su presencia es básica para asegurar una mínima oferta, como Badajoz, Albacete, Logroño, Brugos, León o Salamanca ${ }^{11}$; bien la existencia de cuantiosas pérdidas en la explotación de los servicios con origen o destino en los mencionados aeropuertos ${ }^{12}$.

Estas variaciones del coste por pasajero también se observan en otros países, como ha puesto de manifiesto en Francia el estudio realizado por los tribunales de cuentas regionales sobre los aeropuertos del país. Partiendo de esos datos, Air France calcula que los subsidios que recibe Ryanair oscilarían entre los 9 y los 32 euros por pasajero transportado (Amedeo, 2010a). Aunque los datos no son estrictamente comparables con los de España, porque se recoge una síntesis de varios años que además computa las exenciones y/o rebajas de algunas tasas aeroportuarias, se observa claramente que el coste por pasajero está relacionado con el tráfico de la compañía en cada aeropuerto. Pero también se constata que dicho coste es mucho mayor en Francia que en España -algo que en parte podría explicarse por las bajas tarifas aeroportuarias que se aplican en nuestro país (MFOM, 2008)- y que las diferencias entre aeropuertos son inferiores en Francia, pues presentan una relación de 1 a 3,5.

También conviene señalar que, en algunos aeropuertos donde la presencia de Ryanair es más dilatada, al analizar la evolución de las subvenciones y de los pasajeros transportados, no se mantiene la relación inversa entre ambas variables antes indicada (tabla 4). En Santander se ha pasado de una ayuda de 3,3 euros por pasajero en 2004 a otra de 5,2 euros en 2009, cuando el tráfico casi se ha multiplicado por nueve. En Reus se detecta una situación similar, duplicándose el tráfico entre 2007 y 2009 al tiempo que la subvención subía de 1,6 euros a 2,3 euros por pasajero. Ello se explica en parte porque el crecimiento de pasajeros no se debe tanto a la consolidación de las rutas ya operadas durante algunos años, sino al tráfico que genera la apertura de nuevas conexiones. En Girona no se aprecia este hecho, a pesar de que la progresión del número de rutas operadas por Ryanair ha sido notable. El elevado uso del aeropuerto que hacen los residentes en el área metropolitana de Barcelona puede ayudar a explicar esta diferencia, pues el mercado potencial para cualquier ruta no puede compararse con el que se puede alcanzar en Santander, a pesar de la proximidad de Bilbao, ni en Reus, que es mucho menos usado por los habitantes de la capital catalana.

11 Los datos de estos tres últimos se presentan agregados junto con los de Valladolid, ya que la Junta concede ayudas a Air Nostrum para operar en los cuatro aeropuertos, sin detallar la cuantía específica que le corresponde a cada uno de ellos en función de las rutas establecidas.

12 A este respecto, recordemos que en el aeropuerto de Badajoz la existencia de vuelos regulares siempre ha estado supeditada a las ayudas públicas, primero de la Diputación Provincial y posteriormente de la Junta de Extremadura, cancelándose las operaciones cuando no se ha llegado a acuerdos con las aerolíneas (AENA, 1996b, 52). 
Tabla 4

EVOLUCIÓN DEL COSTE ECONÓMICO POR VUELO Y PASAJERO EN ALGUNOS AEROPUERTOS

\begin{tabular}{|c|c|c|c|c|c|c|c|}
\hline Compañía & Aeropuerto & Año & Pasajeros & Vuelos & Subvención (€) & $€ / \mathrm{Pax}$ & $€ /$ Vuelo \\
\hline \multirow{8}{*}{ Ryanair } & \multirow{3}{*}{ Santander } & 2004 & 72.309 & 516 & 241.500 & 3,34 & 468,0 \\
\hline & & 2007 & 305.954 & 2.153 & 1.134 .667 & 3,71 & 527,0 \\
\hline & & 2009 & 617.351 & 4.744 & 3.200 .000 & 5,18 & 674,5 \\
\hline & \multirow{3}{*}{ Girona } & 2004 & 2.417 .429 & 16.175 & 3.100 .000 & 1,28 & 191,7 \\
\hline & & 2007 & 4.259 .715 & 28.559 & 3.500 .000 & 0,82 & 122,6 \\
\hline & & 2009 & 5.043 .517 & 35.318 & 4.633 .333 & 0,92 & 131,2 \\
\hline & \multirow{2}{*}{ Reus } & 2007 & 603.696 & 3.793 & 1.000 .000 & 1,66 & 263,6 \\
\hline & & 2009 & 1.182 .323 & 8.740 & 2.750 .000 & 2,33 & 314,6 \\
\hline
\end{tabular}

FUENTE: Base de datosde ayudas públicas y estadísticas oficiales AENA [www.aena.es].

De lo expuesto podría concluirse que si Ryanair es capaz de aportar un mayor número de pasajeros a un coste muy inferior que el de Air Nostrum, las administraciones públicas podrían comenzar a relegar a la franquiciada de Iberia a un segundo plano. El equilibrio en el reparto de fondos ya se ha alcanzado en el año 2010 y la reciente apuesta de la Generalitat Valenciana por Ryanair, después de haber financiado generosamente a Air Nostrum desde 1996, parece marcar un punto de inflexión en la posición de privilegio mantenida hasta ahora por esta última. La cuestión clave es si Ryanair podría comenzar a hacerse con las conexiones internas explotadas por Air Nostrum.

La respuesta no es sencilla por varios motivos. Recordemos que la presencia de Air Nostrum en la mayoría de aeropuertos del país, especialmente en los de menor tráfico, asegura una amplia cobertura territorial para los tráficos de alimentación del hub de Iberia en Madrid. Ese papel clave se refuerza tras la decisión de Iberia de potenciar los vuelos intercontinentales desde Barcelona, ya que Air Nostrum, junto con Vueling, también asumirá la función de aporte de pasajeros en El Prat. Por tanto, no parece previsible que, aún desapareciendo las ayudas y ofertando Ryanair los mismos servicios, la compañía valenciana abandone las rutas centradas en Madrid y Barcelona. Ello se ha comprobado en varios enlaces donde esta situación ha acontecido, como Santander-Madrid, Almería-Madrid o Valencia-Madrid ${ }^{13}$. Otra cosa es lo que pueda suceder con las relaciones transversales, aquellas que conectan aeropuertos al margen de Madrid y Barcelona. De hecho, la irrupción de Ryanair en algunas de ellas ya ha generado la retirada de Air Nostrum de varias conexiones entre aeropuertos del centro-norte peninsular y del sur (Santander-Alicante, Santander-Málaga, Valladolid-Málaga y Zaragoza-Sevilla). Ello podría extenderse a los vuelos con Canarias después de la apertura de las bases de Ryanair en Tenerife Sur, Gran Canaria y Lanzarote.

En todo caso, como acertadamente ha señalado Dobruszkes (2007, 38), Ryanair sólo tiene interés en conexiones que pueden alcanzar la rentabilidad a medio plazo, como lo demuestra el hecho de que fundamentalmente opera rutas que involucran un mercado emisor o receptor de cierta entidad. En los casos antes señalados, es evidente que Alicante, Málaga y Sevilla cumplen con ese requisito. Cuando esa circunstancia no se dé, parece poco probable

13 El abandono de esas rutas sí que podría producirse cuando los trenes de alta velocidad lleguen a la T4 de Barajas y aseguren una óptima intermodalidad tren-avión para esos destinos. 
que la compañía irlandesa muestre algún interés en el establecimiento de una nueva ruta en ausencia de cuantiosas ayudas que sufraguen las más que probables pérdidas asociadas a su explotación. Una vez agotados los subsidios, el cese de los servicios sería inmediato, tal y como ha ocurrido en varias ocasiones.

\section{CONCLUSIONES}

La liberalización del mercado comunitario de transporte aéreo y la prohibición de las ayudas de Estado, más que acabar con la inversión pública en el sector, han dado lugar a la aparición de diversas fórmulas para la transferencia de esas ayudas, cada vez más asociadas a los incentivos por la apertura de nuevas rutas. A este respecto, la singularidad del caso español radica en el olvido absoluto de los mecanismos previstos en la legislación comunitaria, prefiriéndose otras fórmulas, de discutible legalidad y eficacia. La contratación de publicidad turística, bien de forma transparente, bien mediante acuerdos confidenciales, se ha convertido en el mecanismo preferido por los poderes públicos para negociar el establecimiento de una compañía o la implantación de una nueva ruta.

Con el objeto de conocer el montante de las ayudas públicas transferidas a las aerolíneas y evaluar la magnitud de esta práctica en España, los autores han elaborado una detallada base de datos que ofrece la primera aproximación fiable al fenómeno. Ahora bien, las dificultades encontradas para confeccionar la misma y la necesidad de recurrir a fuentes escasamente difundidas, evidencian una notable falta de transparencia en el manejo de los fondos públicos, que llega al extremo de intentar escamotear al control parlamentario la documentación que recoge las contraprestaciones asociadas dichos subsidios.

Se esté de acuerdo o no con la generalización de incentivos a las compañías aéreas para estimular la oferta de vuelos de un aeropuerto, contar con una normativa clara y detallada, abierta a todos los operadores y que vincule las ayudas económicas a objetivos tangibles (número de pasajeros transportados, rutas abiertas, frecuencias semanales operadas...), es mucho más deseable que la opacidad imperante hasta el momento. Sólo así quedarían asegurados los principios de publicidad, transparencia y libre concurrencia que deben guiar la actuación de las administraciones públicas.

La transparencia en la asignación redunda en un mejor control sobre el destino de los fondos públicos y la relación entre incentivos y objetivos reduce la subordinación de las instituciones a los intereses de las aerolíneas. Como ha señalado repetidas veces para el caso valenciano la Sindicatura de Comptes $(2006,149)$, la ausencia de una valoración de los resultados obtenidos mediante dichos contratos constituye una notable debilidad de los mecanismos hasta ahora utilizados. Ello también permitiría conocer la viabilidad real de las rutas, pues la normativa comunitaria obliga a un descenso progresivo de las ayudas y a una duración máxima de tres años, condiciones que se incumplen sistemáticamente en España. Por ello, llama la atención que AENA, el ente público propietario de la mayoría de los aeropuertos españoles, no haya impulsado ningún esquema de ayudas para facilitar la apertura de nuevas rutas ${ }^{14}$, optando

14 Los cambios que se avecinan con la nueva política aeroportuaria del Gobierno español hacen pensar que este tipo de estrategias puedan comenzar a aplicarse a medio plazo. A este respecto, lo relevante no es tanto la división de AENA en dos organismos, uno estatal dedicado al control de la navegación aérea y otro encargado de la administración de los aeropuertos, sino la posible segregación de algunas instalaciones de este último ente, cuya gestión podría cederse total o parcialmente o otros actores públicos y/o privados. 
primero por la fórmula de los Comités de Desarrollo de Rutas ${ }^{15}$, cuyo impacto ha sido nulo y más recientemente por un cambio de los criterios de fijación de las tasas aeroportuarias para el año 2011, que ha sido criticado por su supuesta $\operatorname{arbitrariedad}^{16}$.

Si bien los esquemas de incentivos serían una opción para las rutas con función turística, en aquellas que presentan una función de desenclave territorial ${ }^{17}$, habría que recurrir a la declaración de obligaciones de servicio público. Ahora bien, ello tendría que justificarse sólidamente, ya que a medida que se consolida el ferrocarril como alternativa de desplazamiento rápido, carece de toda lógica subvencionar una conexión aérea concurrente. La reciente imposición de OSP en la ruta Almería-Sevilla es un claro ejemplo de cómo debiera procederse en estos casos, demostrando que no es descabellado que algunas rutas intrapeninsulares puedan explotarse en este régimen. ${ }^{18}$

Por otro lado, conviene resaltar que las compañías de bajo coste suponen un menor coste para las administraciones públicas que utilizan incentivos económicos para facilitar la apertura de una ruta. Aunque no todas las rutas y aeropuertos son iguales, estos resultados nos llevan a pensar que las preferencias de las instituciones pueden cambiar, decantándose cada vez más por las aerolíneas low cost y en menor medida por Air Nostrum. Lo ocurrido en Valencia con el último concurso de inserción de publicidad en aeronaves constituye un paso en esa dirección ${ }^{19}$, si bien está por ver su generalización a otros lugares.

En todo caso, si las administraciones terminan decantándose por compañías de bajo coste, deberían cuestionarse si las tarifas reducidas suponen una maximización del bienestar. O si por el contrario, los costes sociales (O'Sullivan y Gunnigle, 2009), ambientales (EEA, 2008) y energéticos (Nygren et al., 2009) que implican propician un balance negativo. La generalización del modelo de bajos precios ha terminado inculcando entre amplias capas de la sociedad una cultura de la competencia que alcanza extremos insospechados, enfrentando

15 En diciembre de 2009, la Secretaría de Estado de Turismo y AENA firmaron un acuerdo con el objetivo de potenciar la constitución de estos Comités (MFOM y MITYC, 2009), si bien únicamente el previsto para Galicia ha llegado a funcionar. Su recorrido ha sido corto, puesto que las desavenencias entre algunos alcaldes ha impedido cerrar una estrategia conjunta, con lo que cada institución va a continuar negociando por separado la implantación de nuevas rutas (Obelleiro, 2010).

16 Que las tasas de Girona sean un $27 \%$ inferiores a las de otros aeropuertos con su mismo volumen de pasajeros parece una clara cesión a los intereses de Ryanair (Otero, 2010b). Recordemos que la compañía irlandesa, tras la apertura de su base de Barcelona, había solicitado la bajada de las tasas de Girona y Reus para mantener su presencia en los mismos.

17 La función de desenclave aparece muy vinculada a la política francesa de ordenación del territorio y a su objetivo de reducir los desequilibrios existentes en el país. En ese sentido, desenclavar un territorio supone mejorar sus condiciones de acceso a los nodos y redes que estructuran los grandes flujos económicos (Debrie y Steck, 2001, 29). De ahí que el transporte aéreo se convirtiera en un instrumento más de la política de ordenación del territorio, ya que una conexión aérea podía ser básica para el desenclave de ciertos territorios (Dupéron, 2000, 41). Algunas de las rutas subsidiadas en España pueden encajar plenamente en dicho perfil.

18 En Portugal existe otro precedente, ya que la ruta Bragança-Vila Real-Lisboa se explota en régimen de OSP desde 1997, justificándose esta declaración por el elevado tiempo de viaje que conlleva un desplazamiento terrestre entre la capital del país y las ciudades trasmontanas, así como por su reducido mercado potencial, lo que dificulta que la ruta sea operada con algún margen de rentabilidad económica.

19 La compañía irlandesa se ha hecho con el contrato de publicidad tras presentar una oferta de 1,5 millones de euros, que rebajaba en un $90 \%$ el presupuesto inicial de la licitación, fijado en 16 millones. La oferta de Air Nostrum ascendía a 9,8 millones, cuando en otros concursos de estas características apenas introduce rebaja alguna sobre el valor estipulado inicialmente (El País, 2010). 
sociedades y territorios por una porción de cuota de mercado. Así, mientras Ryanair anuncia el cierre de su base de Marsella, en protesta por la investigación judicial abierta tras denunciarse que el personal contratado en la misma está sujeto a la legislación laboral irlandesa (Amedeo, 2010b), el director del aeropuerto de Girona veía este hecho como una oportunidad de potenciar su aeropuerto (Europa Press, 2010b). Ni la más mínima preocupación por el cumplimiento de la legislación vigente o por la práctica encubierta de dumping social en el seno de la Unión Europea, si ello redunda en el aumento del número de pasajeros de la instalación que gestiona.

\section{BIBLIOGRAFÍA}

ADEY, P., BUDD, L. y HUBBBARD, P. (2007): «Flying lessons: exploring the social and cultural geographies of global air travel». Progress in Human Geography, 31(6), 773791.

AEROPUERTOS ESPAÑOLES Y NAVEGACIÓN AÉREA (AENA). (1996): Los aeropuertos españoles. Su historia 1911 - 1996. Tomo II. Madrid, AENA.

AIPORT REGIONS CONFERENCE (ARC). (2005): ARC's contribution to the Public Consultation for the "Community guidelines on financing of airports and start-up aid to airlines departing from regional airports» (Nota de prensa. Gotemburgo, 07/03/2005).

ALONSO, J. (2010, 7 de mayo): «Ryanair cobrará 17,4 millones en ayudas públicas sin dar una fecha para abrir su base de operaciones». Heraldo de Aragón, p. 5.

AMEDEO, F. (2010a, 11 de marzo): «Air France a porté plainte contre Ryanair». Le Figaro.

AMEDEO, F. (2010b, 20 de mayo): «Ryanair menace de quitter Marseille». Le Figaro.

ANA (2008): Relatório Anual 2007 - Relatório de Gestão e Contas. Lisboa, Aeroportos de Portugal, S.A.

BERKELEY HANOVER CONSULTING (BHC). (2000): The Impacts of Future Aviation Growth in the UK. Londres, Strategic Aviation Special Interest Group of the Local Government Association (SASIG).

BOLETÍN OFICIAL DE ARAGÓN (BOA). (1999): DEPARTAMENTO DE ORDENACION TERRITORIAL, OBRAS PUBLICAS Y TRANSPORTES - ORDEN de 28 de diciembre de 1998, del Departamento de Ordenación Territorial, Obras Públicas y Transportes, por la que se da publicidad a las subvenciones concedidas en el ejercicio 1998, por la Dirección General de Carreteras, Transportes y Comunicaciones. (Diario n ${ }^{\circ}$ 7, 20 de enero de 1999, pp. 270-276).

BOLETÍN OFICIAL DE LA REGIÓN DE MURCIA (BORM). (1996): Consejería de Política Territorial y Obras Públicas - ORDEN de 3 de abril de 1996, por la que se convocan ayudas para la implantación, promoción y difusión de servicios aéreos regulares de pasajeros con el Aeropuerto de San Javier. (Diario n ${ }^{\circ} 79,6$ de abril de 1996, pp. 3427-3428).

CINCO DÍAS (2004, 25 de octubre): «Air Nostrum recibió 9,9 millones de organismos públicos el año pasado». Cinco Días.

COMISIÓN DE LAS COMUNIDADES EUROPEAS (CCE) (1992): Report by the Commission to the Council and the European Parliament on the evaluation of aid schemes stablished in favour of Community air carriers (SEC (92) 431 final). Luxemburgo, Oficina de Publicaciones Oficiales de las Comunidades Europeas. 
COMISIÓN DE LAS COMUNIDADES EUROPEAS (CCE) (2007): Questions on State aid for Airports and start-up aid to airlines. (Nota de prensa (MEMO/07/285) - Bruselas, 10/07/2007).

COUR DES COMPTES (CC). (2008): Les aéroports français face aux mutations du transport aérien. Paris, La Documentation Française.

DEBRIE, J. y STECK, B. (2001): «L'enclavement, réévaluation théorique et application à l'Afrique de l'Ouest». L'Espace géographique, 30(1), 26-36.

DIARIO DE SESIONES DEL PARLAMENTO DE NAVARRA (DSPN) (2008): Pregunta sobre las razones por las que no se aporta la información solicitada sobre el convenio suscrito entre la Compañía Aérea Portugalia/TAP y la Sociedad Pública SPRIN, presentada por el Ilmo. Sr. D. Txentxo Jiménez Hervas. (Diario ${ }^{\circ}{ }^{2} 2$, VII Legislatura, 3 de abril de 2008, pp. 9 y 10).

DIARIO OFICIAL DE LA UNIÓN EUROPEA (DOUE) (2004): Dictamen de iniciativa del Comité de las Regiones sobre el tema «Las compañías aéreas de bajo coste y el desarrollo territorial» (Diario ${ }^{\circ}$ C 318 de 22/12/2004, p. 7-11). Luxemburgo, Oficina de Publicaciones Oficiales de las Comunidades Europeas.

DIARIO OFICIAL DE LA UNIÓN EUROPEA (DOUE) (2008): Reglamento (CE) No 1008/2008 del Parlamento Europeo y del Consejo, de 24 de septiembre de 2008, sobre normas comunes para la explotación de servicios aéreos en la Comunidad (versión refundida) (Diario ${ }^{\circ}$ L 293 de 31/10/2008, p. 3-20). Luxemburgo, Oficina de Publicaciones Oficiales de las Comunidades Europeas.

DIARIO OFICIAL DE LAS COMUNIDADES EUROPEAS (DOCE) (1992): Reglamento (CEE) $n^{\circ}$ 2408/92 del Consejo, de 23 de julio de 1992, relativo al acceso de las compañías aéreas de la Comunidad a las rutas aéreas intracomunitarias (Diario n ${ }^{\circ} 240$ de 24/08/1992 p. 8-14). Luxemburgo, Oficina de Publicaciones Oficiales de las Comunidades Europeas.

DIARIO OFICIAL DE LAS COMUNIDADES EUROPEAS (DOCE) (1994): Aplicación de los artículos 92 y 93 del TCE y del artículo 61 del Acuerdo EEE a las ayudas estatales en el sector de la aviación». (Diario no C350 de 10/12/1994, pp. 5-20). Luxemburgo, Oficina de Publicaciones Oficiales de las Comunidades Europeas.

DIARIO OFICIAL DE LAS COMUNIDADES EUROPEAS (DOCE) (2004): Decisión de la Comisión de 12 de febrero de 2004 relativa a las ventajas otorgadas por la Región Valona y Brussels South Charleroi Airport a la compañía aérea Ryanair con ocasión de su instalación en Charleroi (Diario $n^{\circ}$ L137 de 30/04/2004, pp. 1-62). Luxemburgo, Oficina de Publicaciones Oficiales de las Comunidades Europeas.

DIARIO OFICIAL DE LAS COMUNIDADES EUROPEAS (DOCE) (2005): Directrices Comunitarias sobre la financiación de aeropuertos y las ayudas estatales de puesta en marcha destinadas a compañías aéreas que operen desde aeropuertos regionales (Diario n ${ }^{\circ}$ C312 de 09/12/2005, pp. 1-14). Luxemburgo, Oficina de Publicaciones Oficiales de las Comunidades Europeas.

DOBRUSZKES, F. (2006): «An analysis of European low-cost airlines and their networks». Journal of Transport Geography, 14(4), 249-264.

DOBRUSZKES, F. (2007): «Une géographie des services publics aériens en Europe». L'Espace Géographique (4), 320-336. 
DOCHERTY, I., GATHER, M. AND SHAW, J. (2004): «Changing roles of the state in 21st century transport». Journal of Transport Geography, 12(4), 257-264.

DOGANIS, R. (2001): The airline business in the 21st century. Londres, Routledge.

DUPÉRON, O. (2000): Transport aérien, aménagement du territoire et service public. Paris, L'Harmattan.

EL PAÍS. (2010, 17 de noviembre): «Air Nostrum mantendrá su política tras perder ayudas públicas frente a Ryanair». El País, p. 6, Cuaderno Comunidad Valenciana.

ESCALONA ORCAO, A. I., GÁMIR ORUETA, A., LARRODÉ PELLICER, E., RAMOS PÉREZ, D. y SANAÚ VILLARROYA, J. (2008): Análisis espacial, económico y funcional del aeropuerto de Zaragoza (Documento de trabajo ${ }^{\circ}$ 51). Zaragoza, Fundación Economía Aragonesa (FUNDEAR).

EUROPA PRESS (2010a, 13 de octubre): «El Consorcio del Aeropuerto de León acudirá a la vía judicial por el impago del Ayuntamiento de las cuotas de 2009 y 2010». Gente Digital.

EUROPA PRESS (2010b, 26 de octubre): «Ryanair elimina en invierno siete rutas desde Girona y reduce un 30\% sus frecuencias de vuelo». La Vanguardia.

EUROPEAN LOW FARES AIRLINE ASSOCIATION (ELFAA) (2004a): ELFAA Calls On Transport Ministers To Push Commission for Guidelines On Airport Deals Following the Charleroi Decision (Nota de prensa. Bruselas, 08/03/2004).

EUROPEAN LOW FARES AIRLINE ASSOCIATION (ELFAA) (2004b): ELFAA members concerned over reports of much wider impact from possible EU Commission's draft decision on Ryanair/Charleroi issue (Nota de prensa. Bruselas, 29/01/2004).

FORUM OF EUROPEAN REGIONAL AIRPORTS (FARE) (2005): FARE Analysis on the Memorandum to the Commission on Community Guidelines on financing of airports and start-up aids to airlines departing from regional airports. Pisa.

GÁMIR ORUETA, A. y RAMOS PÉREZ, D. (2011): «Los pequeños aeropuertos regionales de la España peninsular: dinámicas recientes y perspectivas de futuro». Ería n ${ }^{\circ} 84-85$, pp. 75-100.

GERIKE, R. (2007): «Ecological and Economical Impacts of Low Cost Airlines». In S. Gross y A. Schröder (Eds.), Handbook of Low Cost Airlines. Strategies, Business Processes and Market Environment. Berlín, Erich Schmidt Verlag, pp. 185-216.

GRAHAM, A. (2003): Managing Airports: An International Perspective. Cheltenham, Edward Elgar.

GRAHAM, B . y SHAW, J. (2008): «Low-cost airlines in Europe: Reconciling liberalization and sustainability». Geoforum, 39(3), 1.439-1.451.

GROSS, S. y SCHRÖDER, A. (2007): «Basic Business Model of European Low Cost Airlines - An Analysis of Typical Characteristics». In S. Gross y A. Schröder (Eds.), Handbook of Low Cost Airlines. Strategies, Business Processes and Market Environment. Berlín, Erich Schmidt Verlag, pp. 51-76.

HALPERN, N. y NISKALA, J. (2008): «Airport Marketing and Tourism in Remote Destinations: Exploiting the Potential in Europe's Northern Periphery». In A. Graham, A. Papatheodorou y P. Forsyth (Eds.), Aviation and Tourism. Implications for Leisure Travel. Londres, Ashgate, pp. 193-208. 
MINISTERIO DE FOMENTO (MFOM) (2008): Análisis comparativo de costes de escala en aeropuertos europeos. Madrid, Subdirección General de Transporte Aéreo.

MINISTERIO DE FOMENTO (MFOM) (2009): Fomento y la Junta de Andalucía firman el convenio para establecer la ruta aérea Almería-Sevilla como servicio público (Nota de prensa, 04/03/2009).

MINISTERIO DE FOMENTO (MFOM) (2011): El Gobierno autoriza la licitación de los servicios aéreos en rutas aéreas en Canarias (Nota de prensa, 07/10/2011).

MINISTERIO DE FOMENTO (MFOM) y MINISTERIO DE INDUSTRIA TURISMO Y COMERCIO (MITYC). (2009): Industria y Fomento firman un acuerdo de navegación aérea para promover y consolidar las rutas hacia España (Nota de Prensa de 2 de diciembre). Madrid.

NYGREN, E., ALEKLETT, K. y HÖÖK, M. (2009): «Aviation fuel and future oil production scenarios». Energy Policy, 37, 4.003-004.010.

OBELLEIRO, P. (2010, 8 de noviembre): «La Xunta fracasa en su política de fijar un mapa estable de rutas áereas». El País, p. 4, Cuaderno Galicia.

O'SULLIVAN, M. y GUNNIGLE, P. (2009): «Bearing All the Hallmarks of Oppression. Union Avoidance in Europe's Largest Low-cost Airline». Labor Studies Journal, 34(2), 252-270.

OTERO, L. (2010, 9 de octubre): «Ryanair gana la batalla de las tasas». El País, p. 3, Cuaderno Cataluña.

OTTO, C. (2010, 5 de noviembre): «¿Cuánto cuesta que una compañía vuele en un aeropuerto? En Ciudad Real, 2,3 millones». Cotizalia. Disponible en http://www.cotizalia. com/en-exclusiva/cuanto-cuesta-compania-vuele-aeropuerto-ciudad-20101105-60626. html

RAMOS PÉREZ, D. (2006): Cuando el mercado levanta el vuelo. Transporte aéreo, territorio y sustentabilidad en la Unión Europea: un análisis crítico. Salamanca, Departamento de Geografía, Universidad de Salamanca. Tesis Doctoral inédita. Disponible en http://hdl. handle.net/10366/82469

SINDICATURA DE COMPTES. (2006): Informe de Fiscalización de la Cuenta General de la Generalitat del ejercicio 2005 (Volumen III - Empresas públicas y otros entes). Valencia, Generalitat Valenciana.

TOOL, M. R. (1977): «A social value theory in neoinstitutional economics». Journal of Economic Issues, 11(4), 823-846.

WILLIAMS, G. y PAGLIARI, R. (2004): «A comparative analysis of the application and use of public service obligations in air transport within the EU». Transport Policy, 11(1), 55-66. 